\title{
Essential Ingredients to the Dynamics of Westerly Wind Bursts
}

\author{
MINMIN FU \\ Department of Earth and Planetary Sciences, Harvard University, Cambridge, Massachusetts \\ ELI TZIPERMAN \\ Department of Earth and Planetary Sciences, and School of Engineering and Applied Sciences, Harvard University, \\ Cambridge, Massachusetts
}

(Manuscript received 5 September 2018, in final form 26 May 2019)

\begin{abstract}
Westerly wind bursts (WWBs) are brief, anomalously westerly winds in the tropical Pacific that play a role in the dynamics of ENSO through their forcing of ocean Kelvin waves. They have been associated with atmospheric phenomena such as tropical cyclones, the MJO, and convectively coupled Rossby waves, yet their basic mechanism is not yet well understood. We study WWBs using an aquaplanet general circulation model, and find that eastward-propagating convective heating plays a key role in the generation of model WWBs, consistent with previous studies. Furthermore, wind-induced surface heat exchange (WISHE) acts on a short time scale of about two days to dramatically amplify the model WWB winds near the peak of the event. On the other hand, it is found that radiation feedbacks (i.e., changes in the net radiative anomalies accompanying westerly wind bursts) are not essential for the development of WWBs, and act as a weak negative feedback on WWBs and their associated convection. Similarly, sensible surface heat flux anomalies are not found to have an effect on the development of model WWBs.
\end{abstract}

\section{Introduction}

Westerly wind bursts (WWBs) are episodic, anomalous westerly perturbations of the zonal equatorial winds which can result in local reversals of the trade winds. Previous studies have defined them to have a minimum anomalous wind strength ranging from 2 to $5 \mathrm{~m} \mathrm{~s}^{-1}$, with a zonal extent of $5^{\circ}-40^{\circ}$ and duration of 2-30 days, and found their frequency to be around 5 to 15 times per year (Hartten 1996; Harrison and Vecchi 1997; Yu et al. 2003; Seiki and Takayabu 2007a). WWBs are an important component of high-frequency atmospheric wind variability in the tropics, and are known to be important to ENSO dynamics by exciting eastward propagating downwelling Kelvin waves (McPhaden et al. 1992; Kessler et al. 1995). These waves have been shown to cause warming in the eastern Pacific (Giese and Harrison 1991) and have been associated with the onset and amplification of El Niño events (Luther et al. 1983; Latif et al. 1988; Perigaud and Cassou 2000; Lengaigne et al. 2004b).

\footnotetext{
Corresponding author: Minmin Fu, mjfu@g.harvard.edu
}

Because of their short time scale, WWBs were initially considered a "stochastic" forcing of ENSO (i.e., related to short-term weather noise; Moore and Kleeman 1999; Penland and Sardeshmukh 1995). Yet it is now understood that they occur more frequently and extend farther eastward prior to and during warm-ENSO events (Yu et al. 2003; Tziperman and Yu 2007), thus further amplifying developing El Niño events (Eisenman et al. 2005). The observed correlation between WWB parameters and SST (Tziperman and Yu 2007) allows parameterizing these events in an ENSO model (Gebbie et al. 2007; Gebbie and Tziperman 2009a,b), and justifies representing them as multiplicative rather than additive noise (Perez et al. 2005; Jin et al. 2007; Sura and Sardeshmukh 2008).

Because of their importance to ENSO, it is important to better understand why WWBs occur. Early observational studies of individual WWBs leading up to El Niño events (Nitta and Motoki 1987) found that WWBs were coupled to a rapid intensification of convection. Later investigations, based on improved datasets, performed compositing and classification on a large number of WWBs (Harrison and Giese 1991; Harrison and Vecchi 
1997) and found that WWBs were more likely to occur in the boreal winter and less likely to occur during cold ENSO conditions. Westerly wind bursts are found over the tropical Pacific and Indian Oceans, and are not observed over the Atlantic Ocean (Seiki and Takayabu 2007a).

From a modeling perspective, the spatiotemporal distributions of WWBs in the Community Climate System Model (CCSM) and Community Atmosphere Model (CAM) were studied and found comparable to observations in many aspects by Lian et al. (2018). WWBs have been associated with a number of atmospheric phenomena, including cold surges from midlatitudes (Chu 1988), single and paired tropical cyclones (Keen 1982; Nitta 1989), Rossby waves (Kiladis and Wheeler 1995; Puy et al. 2016), and inconclusively, to the Madden-Julian oscillation (Chen et al. 1996; Zhang 1996; Seiki and Takayabu 2007a; Chiodi et al. 2014). Mechanistic studies by Fasullo and Webster (2000) indicated the importance of CAPE accumulation and destruction prior to and during WWBs, and Seiki and Takayabu (2007b) showed the importance of the background zonal wind to the eddy kinetic energy budget of WWBs. Chao and Deng (1998) studied super cloud clusters and found westerly wind signals resembling WWBs, although with a zonal scale that is larger than observed WWBs. They discuss the importance of convection and identified the double cyclone structure north and south of the westerly winds. Because of the large variability of WWBs in strength, duration, structure, and location (Fasullo and Webster 2000), and their complex interaction with tropical atmospheric convection, it is difficult to associate them with any single phenomenon and there is yet no clear consensus on their mechanism (Lengaigne et al. 2004a).

There has been considerable work on the interaction of the Madden-Julian oscillation (MJO; Madden and Julian 1971; Zhang 2005) with ENSO (Kessler and Kleeman 2000; Kessler et al. 1995; Zavala-Garay et al. 2005; Hendon et al. 2007). Furthermore, many ideas have been proposed for the mechanism of the MJO itself, often framed in the context of intraseasonal variability (e.g., Bony and Emanuel 2005; Sobel et al. 2010). These ideas regarding the MJO dynamics share some elements with possible mechanisms for WWBs, and it is therefore important to distinguish between the two, although both involve intraseasonal wind variability. The MJO operates on much larger spatial and temporal time scales than WWBs; furthermore, WWBs have been found to have a much more robust connection with ENSO. There is a debate regarding the correlation and mechanistic connection between WWBs and the MJO (Slingo et al. 1999; Seiki and Takayabu 2007a; Chiodi et al. 2014), and it has been suggested that the MJO modulates the frequency and characteristics of embedded WWBs (Seiki and Takayabu 2007a; Chiodi et al. 2014; Puy et al. 2016). However, as WWBs can occur both in the active and suppressed phases of the MJO, and given the fact that the MJO is one of many factors that can affect WWB frequency, it appears that the presence of an MJO is not strictly necessary to explain the dynamics of WWBs. A recent work by Hayashi and Itoh (2017) attempts to provide a general mechanism for easterly propagating equatorial anomalies that may also be relevant for explaining certain aspects of WWBs.

The purpose of this paper is to investigate the mechanism of WWBs, and, more specifically, to identify those critical physical feedbacks that are essential to the formation of WWBs. We use a zonally symmetric aquaplanet atmospheric general circulation model (GCM). We choose an idealized framework in order to be able to identify the critical ingredients of WWB dynamics. It is possible, of course, that our idealized configuration misses some types of WWBs and this may limit the applicability of our results. Section 2 introduces the methodology, including model setup and WWB detection criteria. Section 3 analyzes the characteristics of WWBs in the control run and then examines the roles of surface flux feedbacks and cloud and radiation feedbacks. We find that radiative feedbacks, including those due to clouds, are comparatively unimportant, but that convective heating plays a dominant role, and that windinduced surface heat exchange (WISHE; Emanuel 1986; Neelin et al. 1987) strongly amplifies the WWBs on a short time scale of about two days near their peak. We conclude in section 4 .

\section{Methodology}

We use the Community Atmosphere Model, version 4 (CAM4) from the Community Earth System Model (CESM) version 1.2.2.1 (Neale et al. 2010) in an aquaplanet configuration with a slab ocean model. The ocean heat transport in the model is specified from a CAM4 control run with fixed SST. The finite-volume core is used, with a resolution of $2.5^{\circ}$ in longitude and $1.9^{\circ}$ in latitude. CAM4 has been found to produce realistic westerly wind bursts of comparable duration, size, and intensity to observations (Lian et al. 2018). Our zonally symmetric aquaplanet control simulation is characterized by mean equatorial easterlies, like the tropical $\mathrm{Pa}$ cific, of an amplitude $4 \mathrm{~m} \mathrm{~s}^{-1}$.

The ocean heat transport (OHT) in the slab ocean simulations reproduces a fixed SST control run climate, in which the SST is prescribed analytically (Medeiros et al. 2016): 
$T(\phi)=\left\{\begin{array}{cc}\frac{1}{2}\left(2-\sin ^{4} \varphi-\sin ^{2} \varphi\right) \delta T+T_{\min }, & \text { if }|\phi|<\frac{\pi}{3}, \\ 0, & \text { otherwise }\end{array}\right.$

where $\phi$ is latitude, $\varphi=(\pi / 2)\left(\phi / \phi_{\max }\right), \phi_{\max }=\pi / 3, \delta=$ $T_{\max }-T_{\min }, T_{\max }=27^{\circ} \mathrm{C}$, and $T_{\min }=0^{\circ} \mathrm{C}$. This SST configuration has been commonly taken as a control experiment in fixed-SST aquaplanet simulations as it produces a robust single ITCZ (Neale and Hoskins 2000).

An advantage of a zonally symmetric aquaplanet is that we may easily composite the detected wind bursts by identifying the longitudinal and temporal coordinates of the day of maximum wind speed, and average over events centered on these two coordinates. For this study we define WWBs to have a raw zonal wind speed greater than $5 \mathrm{~m} \mathrm{~s}^{-1}$, duration of two days or longer, and a zonal extent of at least $10^{\circ}$ longitude. These are similar criteria to those set by prior studies (Puy et al. 2016; Hartten 1996; Vecchi and Harrison 1997; Seiki and Takayabu 2007a; Chiodi et al. 2014). In our control simulation we identify around 15 WWBs per year based on this definition, reasonably realistic given the larger aquaplanet sea surface area.

We perform a mechanism denial study similar to that of Ma and Kuang (2016) to study the importance of physical mechanisms such as surface flux feedbacks, WISHE, and radiative feedbacks. A summary of the experiments is included in Table 1. To include any feedbacks between the SST itself and radiation and surface flux fields, we run all of these experiments in slab-ocean mode with a mixed layer depth of $30 \mathrm{~m}$. To stabilize the climatology, we perform weak nudging of atmospheric temperature throughout the domain for all fixed radiation experiments toward a fixed-SST reference climatology. For fixed surface flux experiments, we do not nudge since the climatology drift is small. For nudging experiments, we closely follow the method of Ma and Kuang (2016) and restore a 1000-day moving average of the temperature field toward the reference state with a restoring time scale of 20 days, which is longer than that used in Ma and Kuang (2016). The longer restoring time scale can still maintain the climatology well and reduces any potential changes to the WWB statistics in the control run, as evidenced by the similarity between CONTROL and NDG (see Fig. 7).

\section{Results}

We aim to identify the main feedbacks participating in the dynamics of WWBs by analyzing them in the control run (section $3 \mathrm{a}$ ), and then by comparing them in runs in
TABLE 1. Summary of experiments performed.

\begin{tabular}{llc}
\hline \hline & \multicolumn{1}{c}{ Process disabled } & Nudging \\
\hline CTL & \multicolumn{1}{c}{-} & $\times$ \\
NDG & \multicolumn{1}{c}{ Interactive latent heat flux } & $\checkmark$ \\
LHFLX & Interactive sensible heat flux & $\times$ \\
SHFLX & WISHE & $\times$ \\
VMAG & Radiative-convective feedback & $\checkmark$ \\
RAD & \\
\hline
\end{tabular}

which different feedbacks such as radiative heating and surface fluxes are eliminated (section $3 b$ ). We find that radiative feedbacks are unimportant for WWBs, but that convection and surface moisture fluxes play a dominant role. In particular, the WISHE feedback acts to strongly intensify WWBs near the time of their maximum strength, causing the wind burst to be highly peaked in time.

\section{a. Characteristics and mechanism of WWBs in the control run}

Figure 1 shows key features of a composited strong WWB from the last 40 years of a $50-\mathrm{yr}$ control run, calculated by averaging over the top $10 \%$ of events sorted by amplitude of peak zonal wind velocity, corresponding to 60 events. Figure 1a, a 3D composite, shows that the surface westerly winds are associated with a strong convective heating anomaly aloft immediately to the east and an elongated negative convective heating anomaly aloft to the west. The lower and upper shadings in Fig. 1 show that the wind event is associated with a strong negative OLR anomaly and a Gill-like convective precipitation pattern (e.g., Barlow et al. 2007) to the east of the convective center (Matsuno 1966; Gill 1980; Zebiak 1982; Kleeman 1991). In our case, the WWB response occurs even without any SST forcing with prescribed zonally symmetric SST (not shown). Also, unlike the Gill's response, it is not characterized by anomalous easterlies to the east of the heating. Closer examination of the convective heating contours in Fig. 1a shows a similar horizontal structure with two off-equator positive anomalies along with an on-equator anomaly to the east. Figures $1 \mathrm{~b}$ and $1 \mathrm{c}$ show Hovmöller diagrams (averaged over $\pm 1^{\circ}$ latitude) of convective precipitation and surface latent heat flux respectively. These two panels indicate that the wind events are associated with eastward propagating latent heat flux and precipitation anomalies. Figure $1 \mathrm{~d}$ shows a snapshot of a composited event at day 0 (the day of maximum winds), showing that the region of westerly winds is coupled to a positive convective precipitation anomaly to the east and a corresponding negative anomaly to the west. The positive precipitation anomaly 

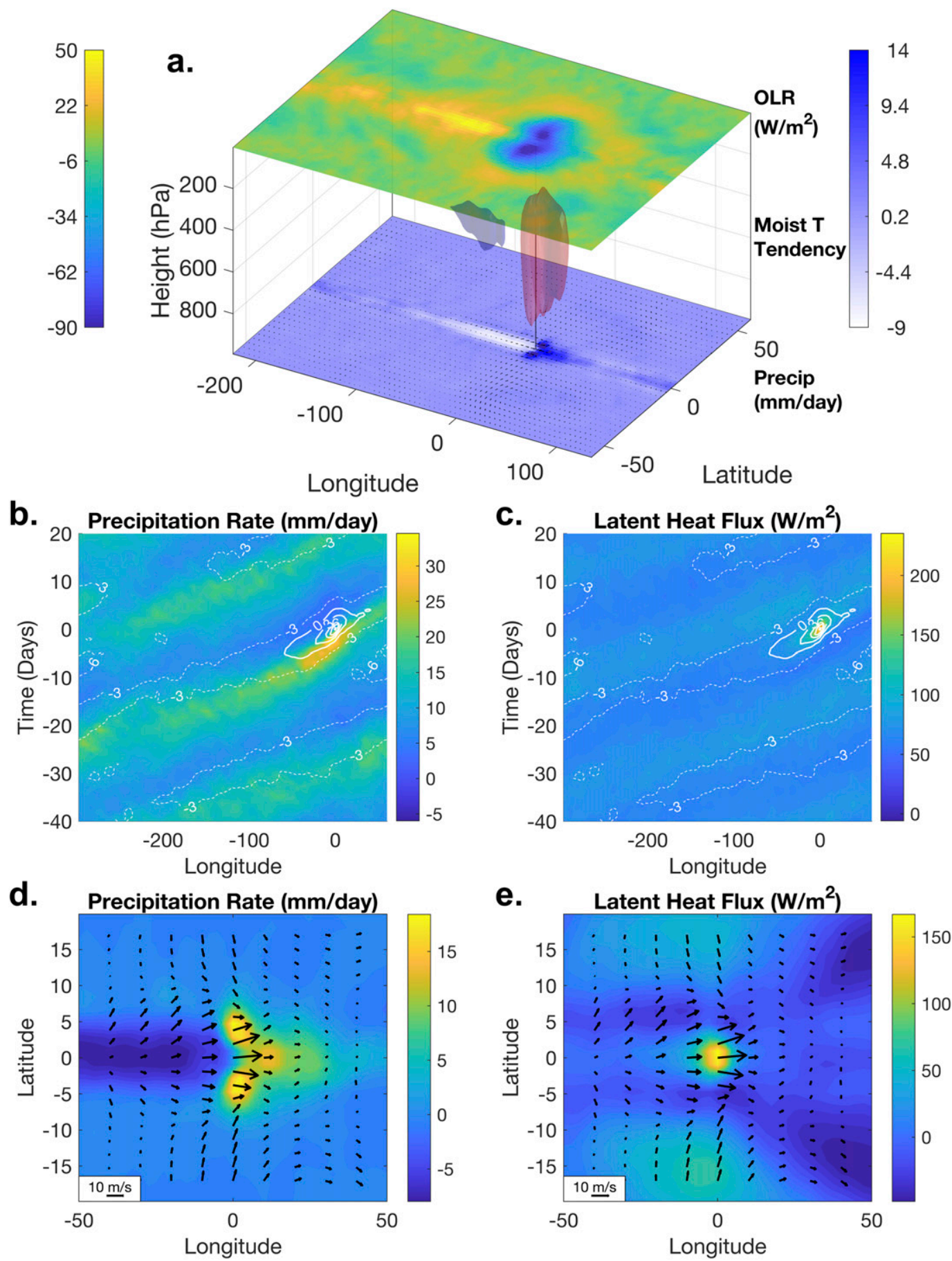

FIG. 1. Characteristics of composited WWBs in the control run. (a) 3D plot of composited strong (top 10\% peak zonal wind) WWBs on day 0 (time of maximum winds). Lower arrows show surface wind anomaly field while lower and upper shading show convective precipitation and OLR anomalies respectively. Red (blue) 3D isosurfaces are of anomalous positive (negative) diabatic temperature tendency due to moist processes. Left color bar is for OLR $\left(\mathrm{W} \mathrm{m}^{-2}\right)$, and right color bar is for convective precipitation $\left(\mathrm{mm} \mathrm{day}^{-1}\right)$. Vertical line shows transect of maximum surface zonal wind. (b) Hovmöller diagram of composited strong WWBs showing convective precipitation (shading) and surface equatorial zonal wind (contours, unit $\mathrm{ms}^{-1}$ ) as a function of longitude and time. (c) Hovmöller diagram of a composited strong WWB showing latent heat flux (shading) and surface equatorial zonal wind (contours, unit $\mathrm{m} \mathrm{s}^{-1}$ ) as a function of longitude and time. (d) Composite snapshot of strong composite WWB at day 0 showing anomaly wind field and contours of anomalous convective precipitation over longitude and latitude. (e) Composite snapshot of strong composite WWB at day 0 showing anomaly wind field and contours of anomaly latent heat flux over longitude and latitude. 


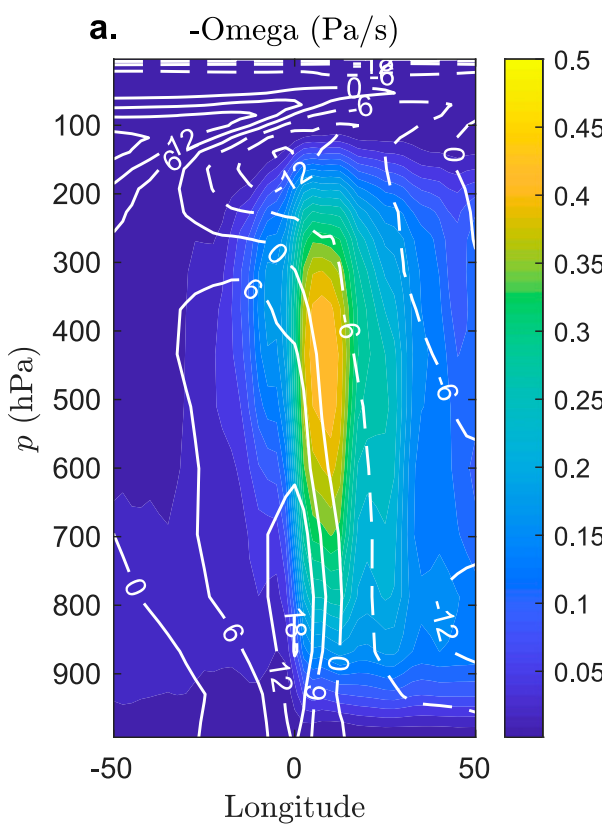

b. Moist DT/Dt (K/day)

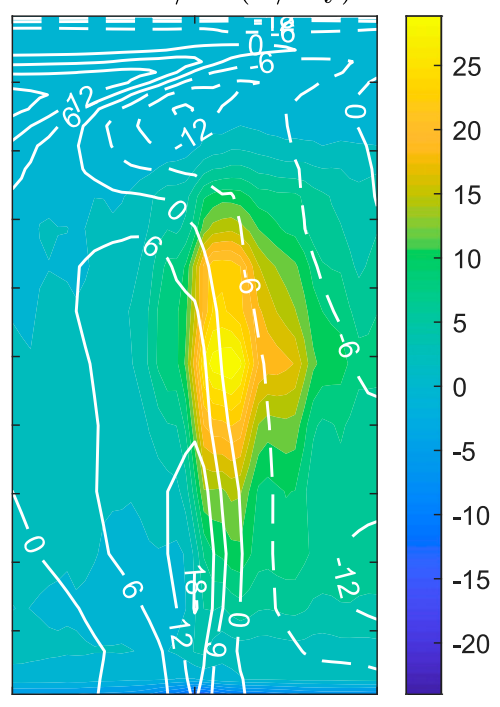

$-50$
0

Longitude c. Cloud Fraction

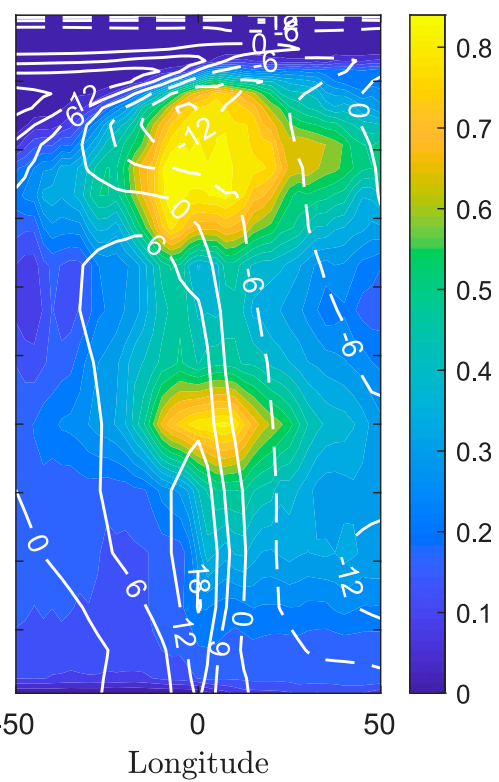

FIG. 2. Longitude-pressure sections from composited strong (top $10 \%$ peak zonal wind) WWBs. White contours are of zonal wind velocity (units $\mathrm{m} \mathrm{s}^{-1}$ ), with shading indicating (a) - omega, (b) $T$ tendency from moist diabatic processes, and (c) cloud fraction.

pattern is again consistent with a Gill response. Figure 1e, of the same event, shows a patch of intense positive latent heat flux anomaly directly collocated with the peak equatorial westerly wind event. In addition, two intense positive latent heat flux anomalies slightly to the west around $\pm 15^{\circ}$ latitude are observed. These indicate an influx of dry air from midlatitudes to the west of the wind burst, leading to enhanced evaporation.

Overall, the control run shows that WWBs are coupled to deep convection anomalies, in agreement with the observations mentioned in the introduction and with the recent modeling study of Lian et al. (2018). This suggests that surface flux and radiative feedbacks are candidates for explaining the mechanism of WWBs. We found that the strongest individual WWBs tend to be associated with twin gyre pairs, while weaker ones were often associated with only a single gyre or none at all. We note that our composited WWB anomaly wind fields are characterized by meridional divergence along the equator while observed WWBs and composites from full GCMs tend to show meridional convergence. On the other hand, WWBs modeled in zonally symmetric aquaplanets (e.g., Chao and Deng 1998) have tended to find meridional divergence. Hence, these differences can thus likely be ascribed to our idealized aquaplanet configuration including the absence of seasonal cycle, lack of topography, and idealized SST configuration and the resulting changes to both the WWB characteristics and the mean state.
This vertical structure is further revealed in Fig. 2 by longitude-pressure sections of the same event depicted in Fig. 1. Figure 2a shows again that the vertical velocity (shading) is to the east of the zonal velocity (white contours), and Fig. 2b shows that the heating is also to the east of the maximum westerly wind. The vertical velocity and moist diabatic heating are maximal near $500 \mathrm{hPa}$ while the cloud fraction has two maxima, at around 600 and $200 \mathrm{hPa}$. This baroclinic structure is reminiscent of that found in the study of super cloud clusters by Chao and Deng (1998).

To further understand the convective processes involved in the WWB dynamics, Fig. 3 shows vertical profiles of temperature tendencies due to shallow convection, deep convection, and stratiform and total moist processes, showing both climatology and a WWB composite averaged temporally over the peak of WWBs and spatially over $\pm 10^{\circ}$ longitude of the location of maximum wind. The WWB composite in Fig. $3 \mathrm{~b}$ indicates that WWBs are characterized by an anomalous shallow convective heating in the lower troposphere and a strong stratiform heating anomaly in the upper troposphere. This results in a total moist convective heating centered around $500 \mathrm{hPa}$. Contributions to the stratiform tendency include the heating from prognostic clouds and from cloud sediment evaporation.

Next, we take a closer look at the time evolution, growth, and decay of WWBs. Figure 4 shows the spatial maximum of anomaly over the equator of various fields 


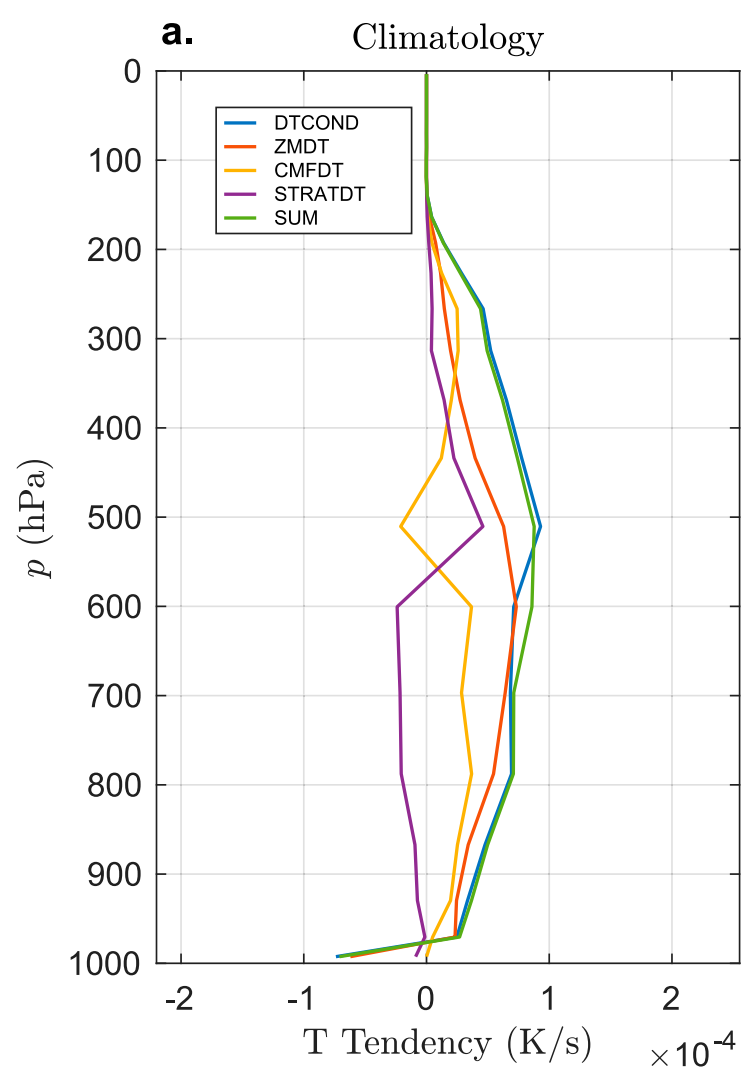

b.

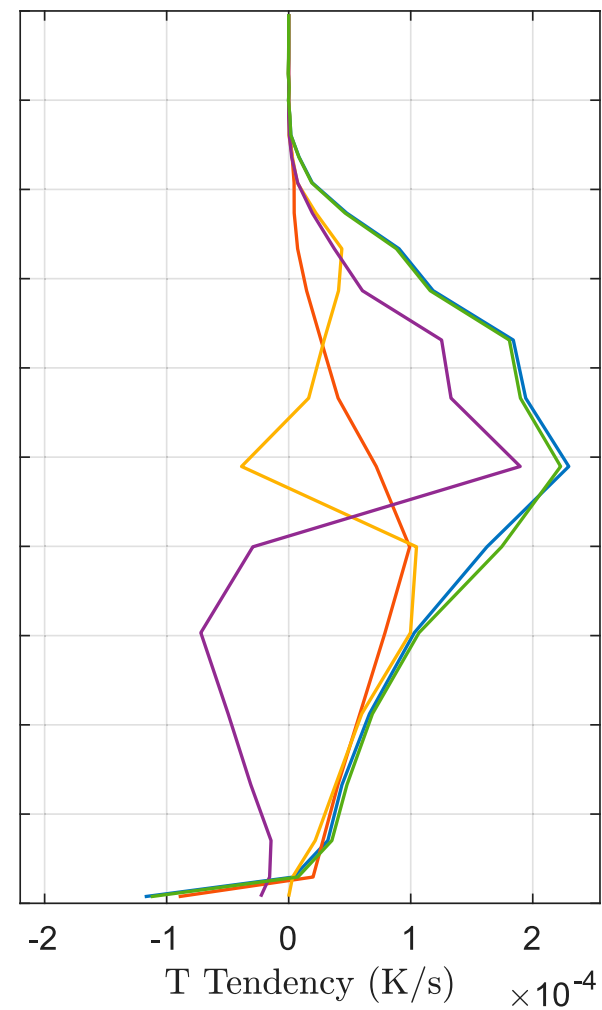

FIG. 3. Vertical profiles of convective heating. (a) Climatology temperature tendency from all moist processes (DTCOND), deep convection (ZMDT), shallow convection (CMFDT), stratiform processes (STRATDT), and the sum of deep, shallow, and stratiform (SUM) over the equator. (b) Composite for strong WWBs averaged over $\pm 10^{\circ}$ longitude at day 0 .

as a function of time for a composited strong WWB. Statistical significance is computed nonparametrically by finding the longitudinal location of the maximum signal at each time, and computing the 5th and 95th percentile values of the signal at this spatiotemporal location over individual events. Regions where zero lies outside of the 5th to 95th percentile limits are considered significantly different from zero and are indicated by a solid line. The westerly wind signal (Fig. 4a) begins to become significant around 5 days before the day of maximum winds ( $t=0$ in the figure), increases rapidly, and then decays on a similar time scale. Figures $4 \mathrm{~b}$ and $4 \mathrm{c}$ show that the peaks in OLR and convective precipitation anomalies on the equator (both indicators of atmospheric convection) precede the wind anomaly, and that the convection signal grows more slowly, on a scale of 20 days compared to 10 days for the winds themselves. This is in agreement with the spatial phase difference observed in the Hovmöller plot in Fig. 1b, showing the shaded precipitation and wind anomaly to be shifted with respect to one another. Last, the spatial maximum of the latent heat flux anomaly (Fig. 4d) is strong, but very brief, indicating that evaporation (to be shown below to be due to the WISHE feedback) is active only within 5 days prior and after the day of maximum wind anomaly.

To investigate the time evolution of the zonal structure of surface fluxes and convection, Fig. 5 shows the zonal wind, OLR, convective precipitation, and latent heat flux anomalies (with respect to climatology) as a function of longitude at various days before and after the day of maximum wind, for a composited strong WWB. The individual events exhibit very noisy signals, and therefore the zonal extent of individual events is much smaller than suggested by the figure (as supported by the histogram of Fig. 7b). We measure statistical significance nonparametrically by constructing a histogram of individual events at each longitude and computing the 5th and 95th percentile values as limits. Regions where zero lies outside of the 5th to 95th percentile limits are considered significantly different from zero and are indicated by a solid line (this is demonstrated for the cyan curves in Fig. 5a, where the 5th and 95th percentiles are shown by thin dashed lines). The fact that the signal is 

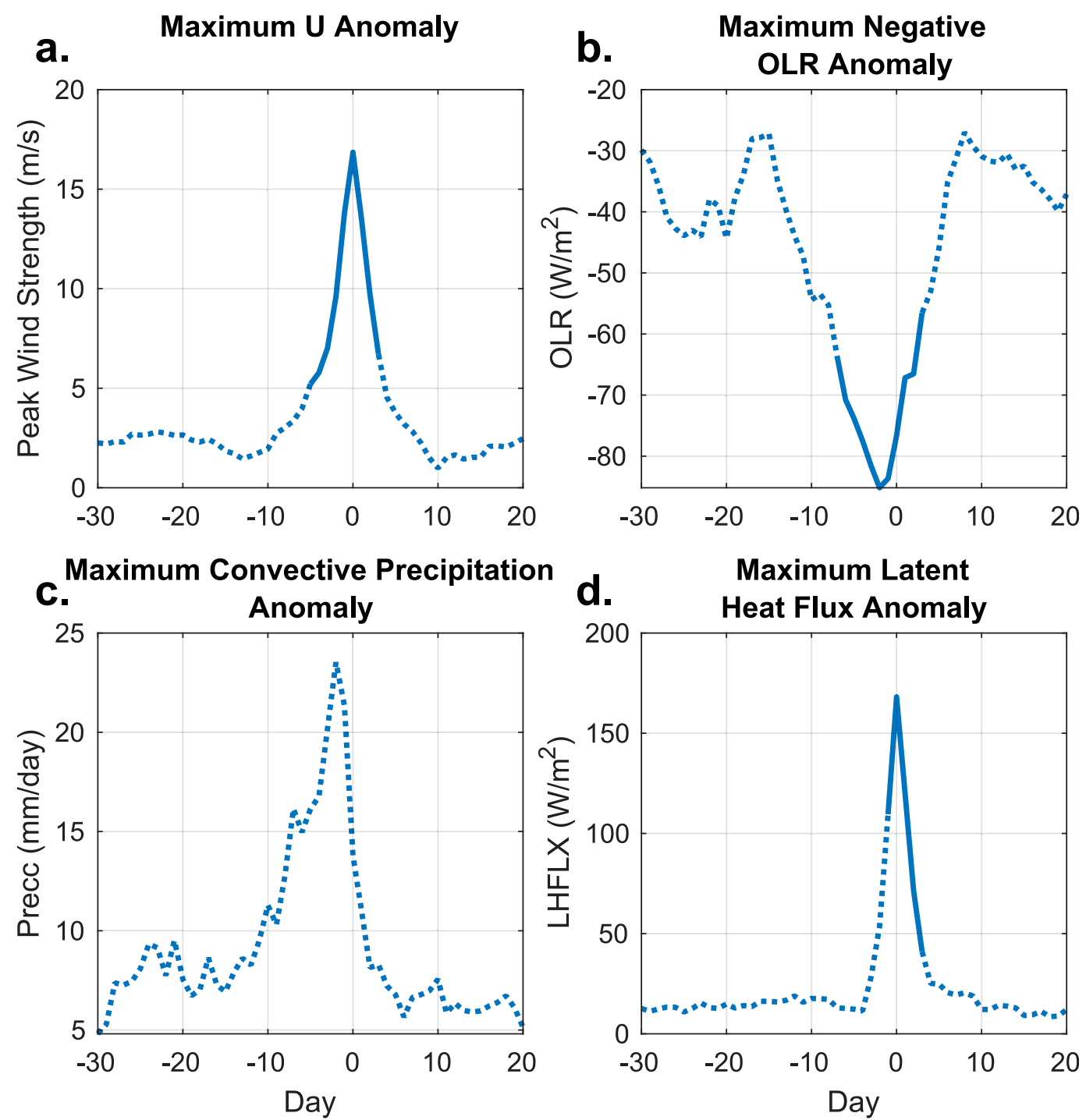

FIG. 4. Composited time series of maximum strong WWB equatorial zonal wind, OLR, convective precipitation, and latent heat flux anomalies as a function of time. Events are composited and averaged over $\pm 1^{\circ}$ latitude, and the maximum value over all longitudes is evaluated at different time lags. Solid lines show statistically significant regions; dotted lines show regions not statistically different from zero. (a) Maximum zonal wind anomaly as a function of time relative to day 0. (b) Maximum negative OLR anomaly as a function of time. (c) Maximum convective precipitation anomaly as a function of time. (d) Maximum latent heat flux anomaly as a function of time.

mostly not statistically significant away from the peak shows that the zonal extent of individual events is small and that our identification criteria selects WWBs rather than large-scale eastward-propagating disturbances in general (e.g., Hayashi and Sumi 1986).

Figure 5a shows the zonal wind anomaly, which moves eastward and becomes more spatially peaked leading up to the day of the event. Figure $5 \mathrm{~b}$ shows corresponding OLR disturbances, with a strong negative peak which increases in magnitude toward day 0 , but does not drastically change in shape. The convective precipitation anomaly (Fig. 5c) clearly shows that convective heating is an important player, yet it reaches its maximum magnitude at around $t=-3$ days. At $t=0$, the maximum on the equator has already moved east of the peak zonal winds, indicating that the convective precipitation signal is both temporally and spatially out of phase with $U$. Finally, the latent heat flux (Fig. 5d) undergoes an explosive growth and then a rapid decay between $t=-3$ and $t=3$ days. We will see below that the WISHE contribution to the latent heat flux is a critical feedback for these WWBs, and that WISHE activates temporally near the peak of the WWB to further amplify it significantly. 

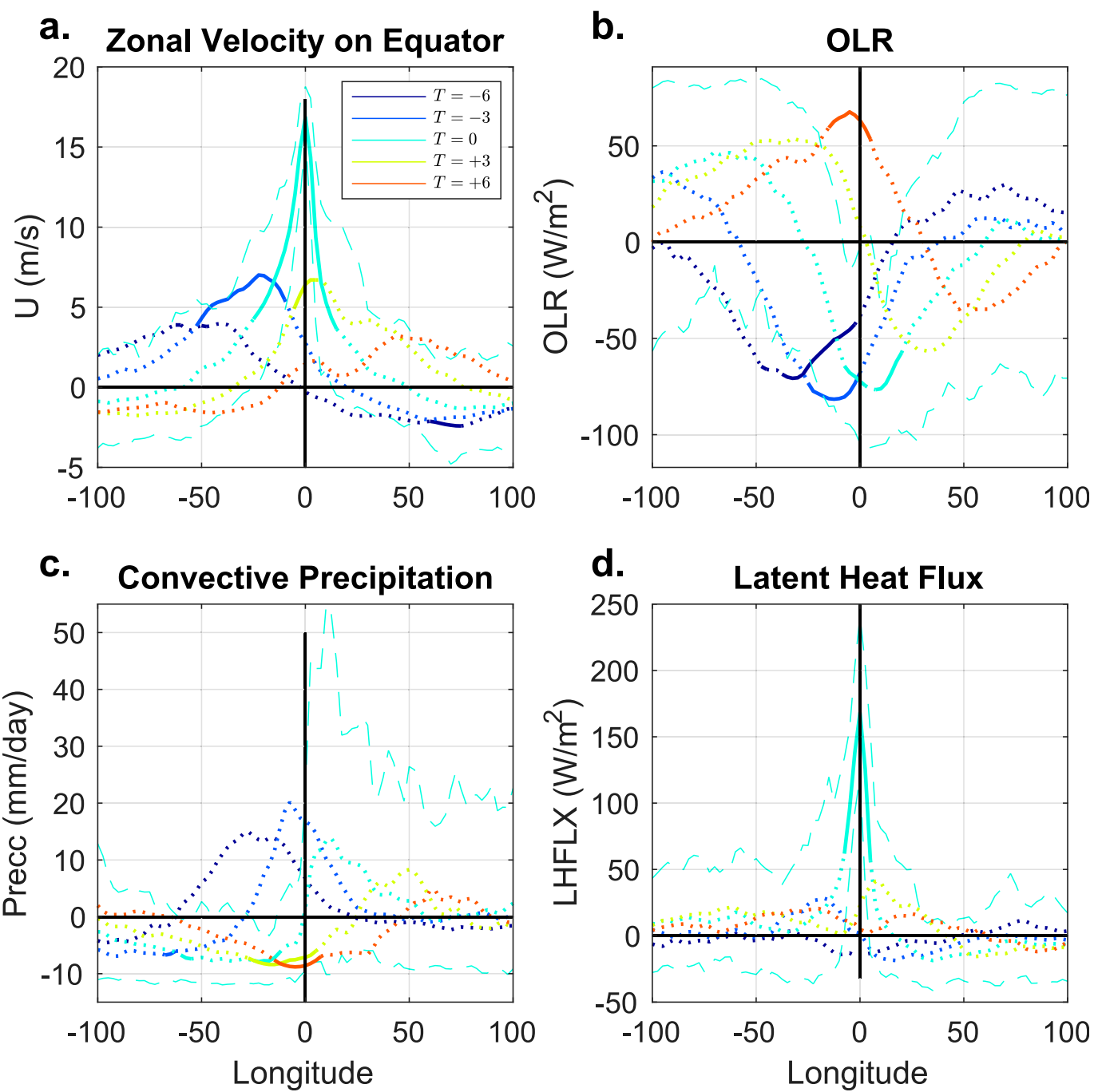

FIG. 5. Composited zonal wind, OLR, convective precipitation, and latent heat flux anomalies from composited strong (top $10 \%$ peak zonal wind) WWBs as a function of longitude taken before and after day of peak winds. Solid lines show statistically significant regions, dotted lines show regions not statistically different from zero. (a) Zonal wind anomaly as a function of longitude. Two dashed lines indicate the 5th and 95th percentile limits. (b) Maximum negative OLR anomaly as a function of longitude. (c) Maximum convective precipitation anomaly as a function of longitude. (d) Maximum latent heat flux anomaly as a function of longitude.

Finally, to see the full spatiotemporal evolution of these events, Fig. 6 shows snapshots of anomalous latent heat flux taken at two day intervals before and after the peak of a composited strong event. A strengthening positive latent heat flux anomaly on the equator flanked by two off-equatorial positive anomalies at latitudes 10-15 steadily propagates to the east, with the winds strengthening until the day of the event, after which the positive latent heat flux anomaly on the equator dissipates. Throughout the duration of the event no corresponding easterly wind anomaly is observed to the east of the convection center, as opposed to the MJO, for example, which is characterized by a westerly wind to the west of the heating and an easterly wind anomaly to its east [e.g., Fig. 15 of Zhang (2005); see also references therein]. Our simulated WWBs are, in fact, characterized by a spatially averaged net westerly wind stress, as observed in Lengaigne et al. (2003).

The equatorward advection of air across contours of surface specific humidity leads to positive latent heat anomalies off the equator at latitudes $10-15$, to the west of the events (e.g., Fig. 10). At the same time, there are two areas of negative latent heat flux anomalies just north and south of the peak westerly wind (latitude 3-10), due to poleward winds bringing moist equatorial air and reducing evaporation. The convergence of dry air occurs 


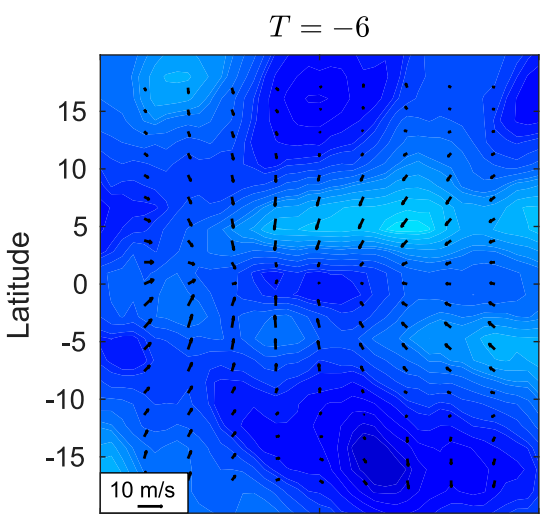

$T=0$

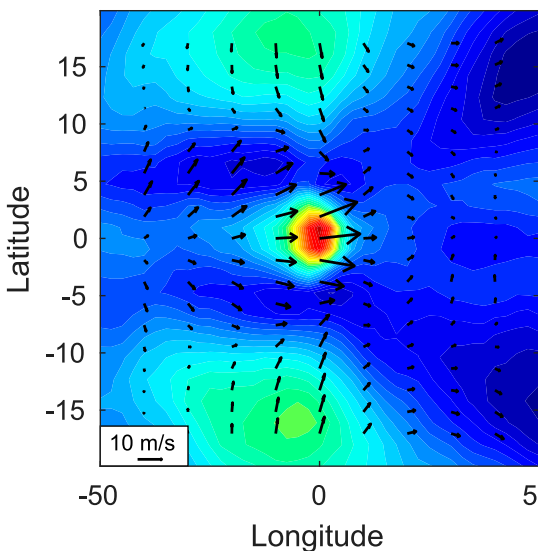

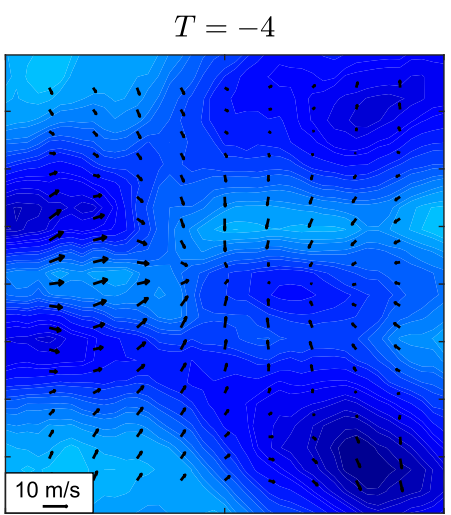

$T=2$

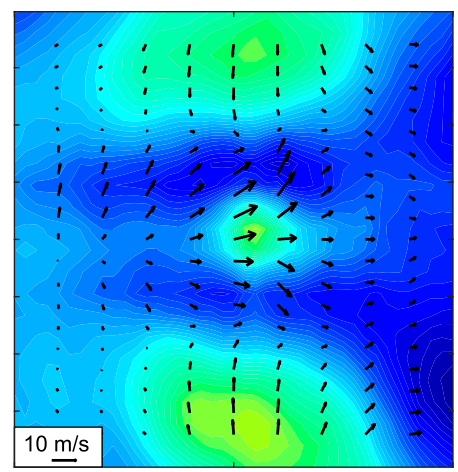

0

Longitude

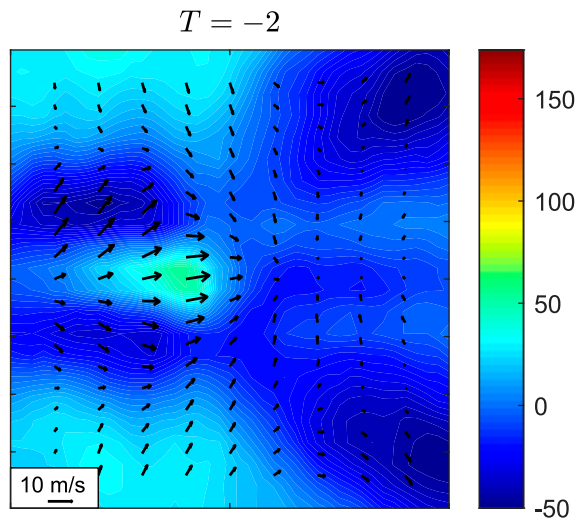

$T=4$

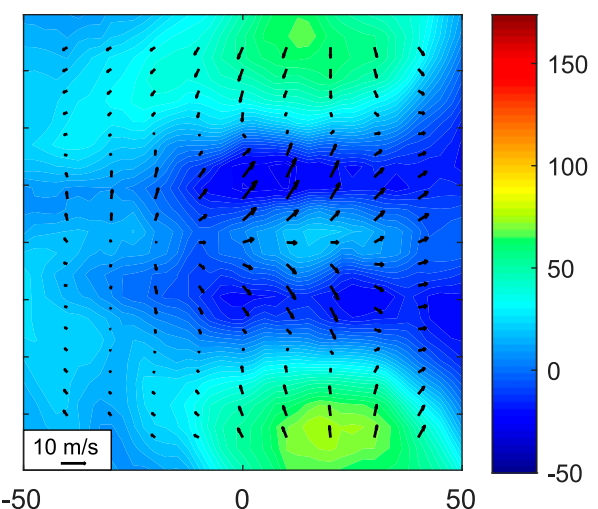

Longitude

FIG. 6. The evolution of a composited strong WWB from the control run. The anomalous wind field (vectors) and anomalous surface latent heat flux (shading, unit of $\mathrm{W} \mathrm{m}^{-2}$ ) are taken at time intervals of 2 days from -6 to +4 days.

from the midlatitudes to the west of the wind event (e.g., $t=0$ in Fig. 8). The spatial scale and structure of the latent heat flux anomaly beneath a WWB are also made clear in the panel corresponding to $t=0$.

Careful study of diagnostics of WWBs on a zonally symmetric aquaplanet reveals important features of the WWB mechanism. WWBs in our model are an eastward propagating convective phenomena characterized by a strong convective heating aloft (Fig. 1) and a brief but intense latent surface heat flux anomaly (Figs. 4 and 5). They are associated with strong vertical motions and with enhanced cloud fraction (Fig. 2) aloft. Hence our improved understanding of WWBs in the control simulation motivates closer investigation of individual processes related to moist convection.

\section{b. Essential ingredients of WWBs}

Motivated by the seeming relevance of OLR, convective heating, and precipitation and latent heat flux anomalies to the dynamics of WWBs, we now try to isolate the role of each of these factors. We first note that an idealized physics component set of CAM4, replacing radiation, convection, and other physics processes by a restoring term to an equilibrium temperature $T_{\text {eq }}$ with a time scale of 40 days and boundary relaxation of 4 days did not produce any WWBs (Held and Suarez 1994). The Held-Suarez model is dominated by baroclinic eddies and does not simulate organized convection in the tropics. This suggests, not surprisingly, that moist convection must play a vital role in WWB dynamics. We now present a series of model experiments disabling various radiative and other feedbacks in examining which of them plays a dominant role in the evolution of WWBs.

We then perform a mechanism denial study similar to that of Ma and Kuang (2016). A summary of the experiments is included in Table 1. An overview of the statistics of the various model runs is presented in Fig. 7, showing probability distribution functions (PDFs) of WWB duration, zonal extent, and peak wind velocity. This figure shows the key ingredients of WWBs are latent heat flux including the WISHE feedback. Remarkably, fixing the radiative forcing to climatology ("Fixed radiation" curves) does not reduce the WWB 

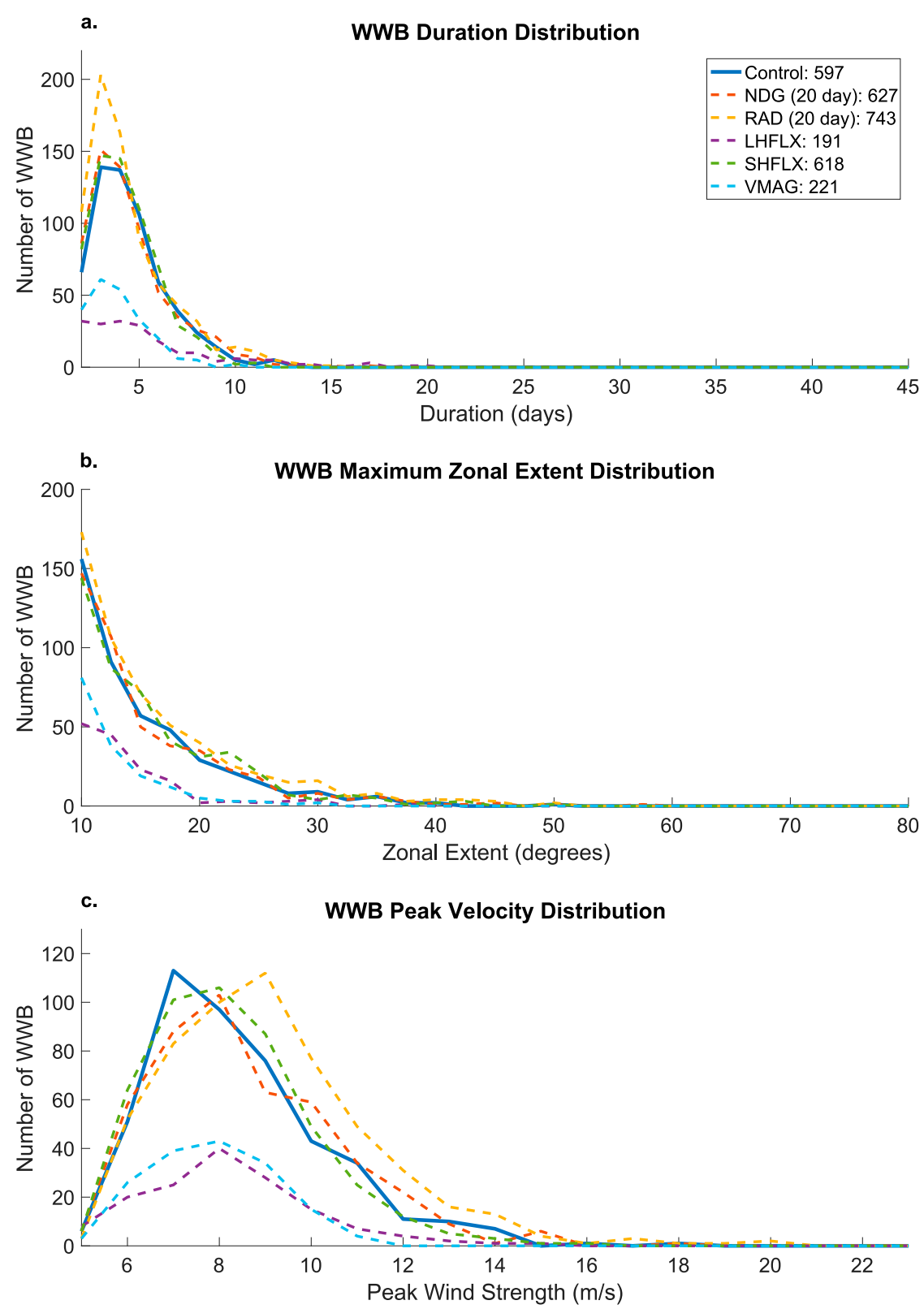

FIG. 7. Statistics of all WWBs in 40-yr control and modified runs. (a) Histogram of the duration of identified WWBs. The number in the legend indicates the number of WWBs identified in each experiment. (b) Histogram of the maximum zonal extent of identified WWBs. (c) Histogram of the maximum wind strength of identified WWBs over 40 years.

frequency, indicating that radiation feedbacks are not a major player. It is interesting to note that WWB frequency in fact increases slightly in the fixed radiation experiments (Fig. 7), which are characterized by stronger precipitation and convection signals (Figs. 8 and 9). As such, combined shortwave and longwave radiative feedbacks may act as a weak negative feedback to suppress WWBs and their associated convection. This is consistent with the findings of Chao and Deng (1998), whose model did not include interactive radiation, yet found large westerly wind patches developing along the equator.

Similarly, setting the sensible heat flux to climatology does not significantly change the WWB distribution. However, when the latent heat flux is set to climatology, the WWB events become much weaker and fewer. In the bulk parameterization for surface evaporation over water 

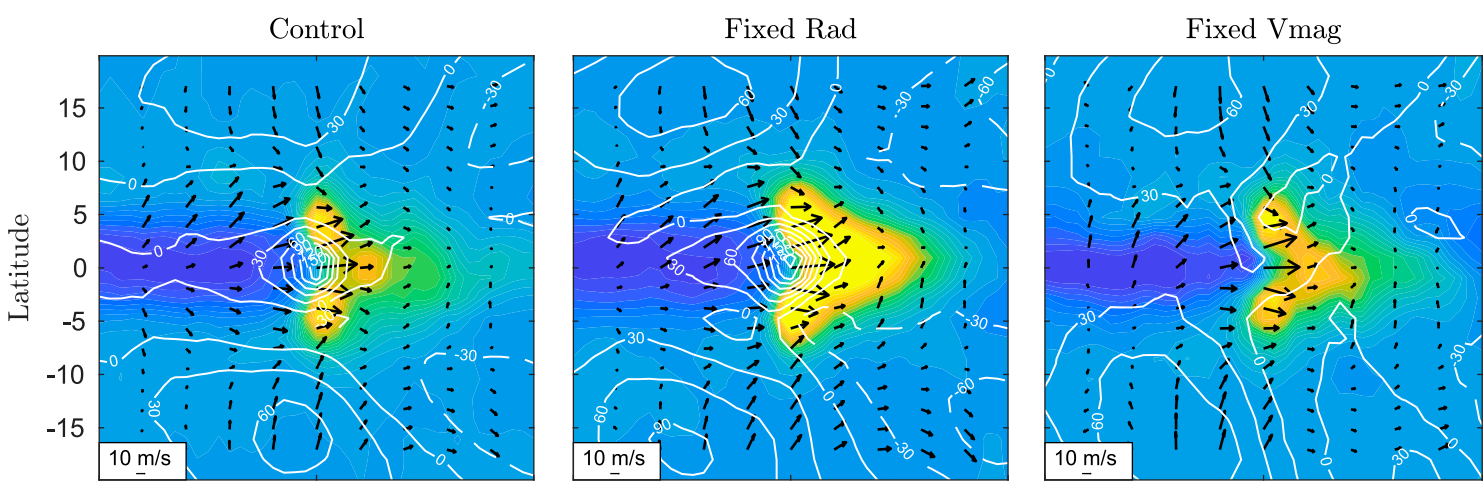

$\times 10^{-8}$
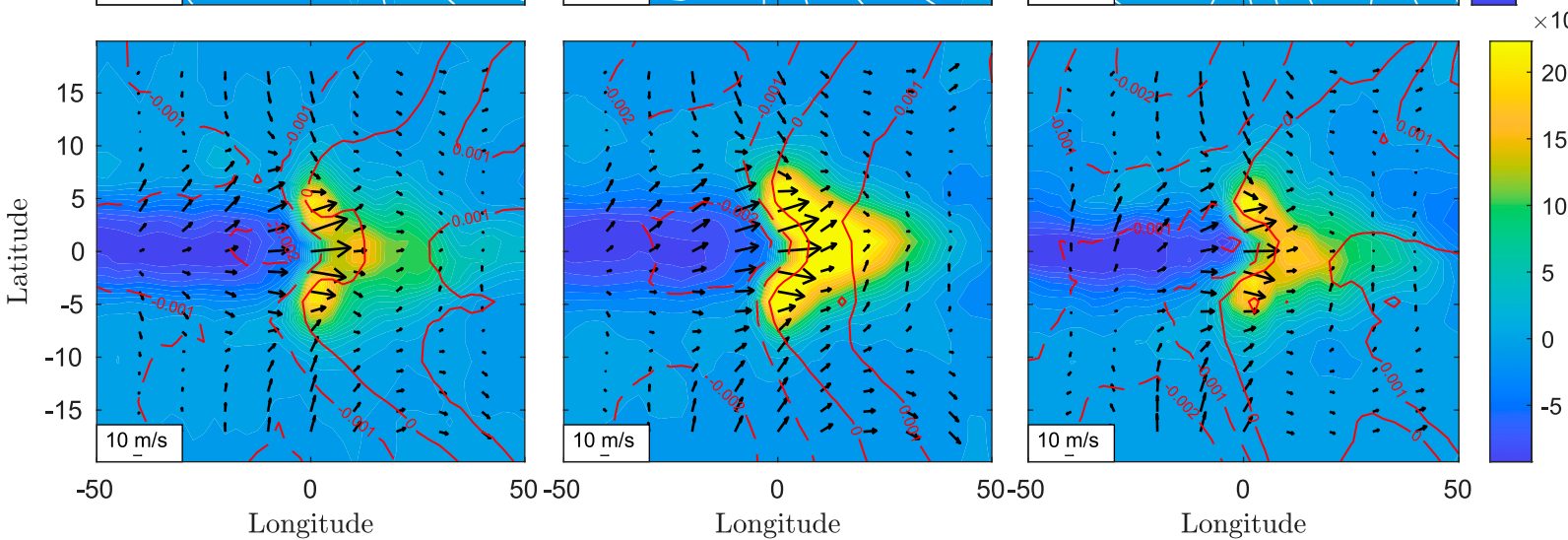

$\times 10^{-8}$

FIG. 8. Comparison of composites of strong events from three main experiments. (from left to right) Control run, fixed radiation, and fixed velocity in bulk formula for latent heat flux. White and red contours indicate latent heat flux anomalies (unit $\mathrm{W} \mathrm{m}^{-2}$ ) and nearsurface specific humidity anomalies (unitless), respectively. Shading indicates convective precipitation anomaly and arrows show the anomaly wind field.

$$
E=\rho_{A}|\Delta \mathbf{v}| C_{E} \Delta q
$$

where $\rho_{A}$ is the atmospheric density and $C_{E}$ is the surface exchange coefficient. The evaporation, or latent heat flux in this case, can be enhanced either through an increase in $\Delta q$ or in $|\Delta \mathbf{v}|$. When the wind velocity in the bulk formula for latent heat flux is set to climatology ("Fixed vmag"), some westerly wind bursts may still occur, but there is a large reduction in the number of events, indicating a major role for the WISHE feedback, by which the westerly wind burst reinforces itself by enhancing latent heat fluxes through the $|\Delta \mathbf{v}|$ term. The diagnostics shown in the previous subsection indicate that the latent heating plays a role only near the very peak of the events, and together with the results here we conclude that WISHE is responsible for the amplification of the WWBs near their peaks, rather than for their very existence.

Next, we compare characteristics of WWBs from three main experiments that further demonstrate some of the above lessons. Figure 8 shows composited snapshots of anomaly latent heat flux, specific humidity, and wind anomalies from the control run (left), fixed radiation (middle), and fixed wind velocity in the bulk formula for latent heat flux (right). The similarity of the composites in the fixed radiation and control cases reinforces the conclusion that radiation is indeed not a major player. The similarity of the composite for the experiment with disabled WISHE feedback ("Fixed vmag") to the control case indicates that although the WISHE mechanism is necessary for explaining the frequency of events, the fewer events that occur in the absence of WISHE remain comparable in terms of precipitation and surface winds. Additionally, we note strong latent heat flux anomalies off the equator to the west, corresponding to the convergence of cold, dry air from the extratropics. The contours of $q$ and latent heat flux are almost collocated in the case of "Fixed vmag" since latent heat flux is no longer sensitive to wind speed. The structure of precipitation and surface $q$ is similar between the three runs, confirming that even without the WISHE feedback, the events are similar, and therefore that WISHE is an amplification mechanism of events that do not owe their existence to this feedback.

To further demonstrate that radiation feedbacks are not essential and better understand the role of WISHE, we next compare the eastward propagation of WWBs in 


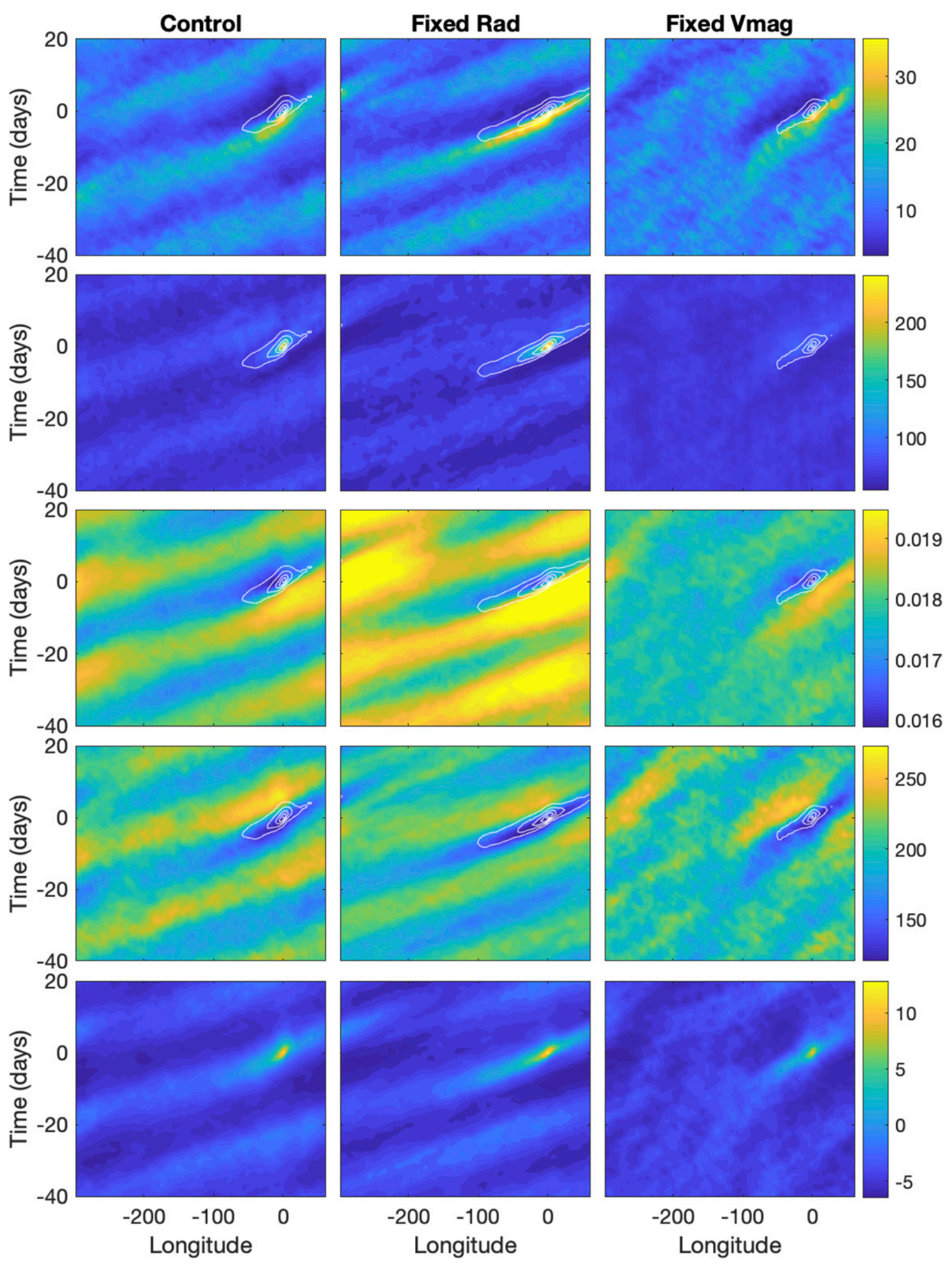

FIG. 9. Hovmöller diagrams of composite strong (top 10\% peak zonal wind) events from three main experiments. (from top to bottom) Hovmöller diagrams of convective precipitation $\left(\mathrm{mm} \mathrm{day}^{-1}\right)$, latent heat flux $\left(\mathrm{W} \mathrm{m}^{-2}\right)$, surface specific humidity (unitless), OLR (W m $\left.{ }^{-2}\right)$, and zonal wind velocity $\left(\mathrm{W} \mathrm{m}^{-2}\right)$. White contours are of positive zonal wind at intervals of $3 \mathrm{~m} \mathrm{~s}^{-1}$. (from left to right) Control run, fixed radiation, and fixed velocity in bulk formula for latent heat flux. 

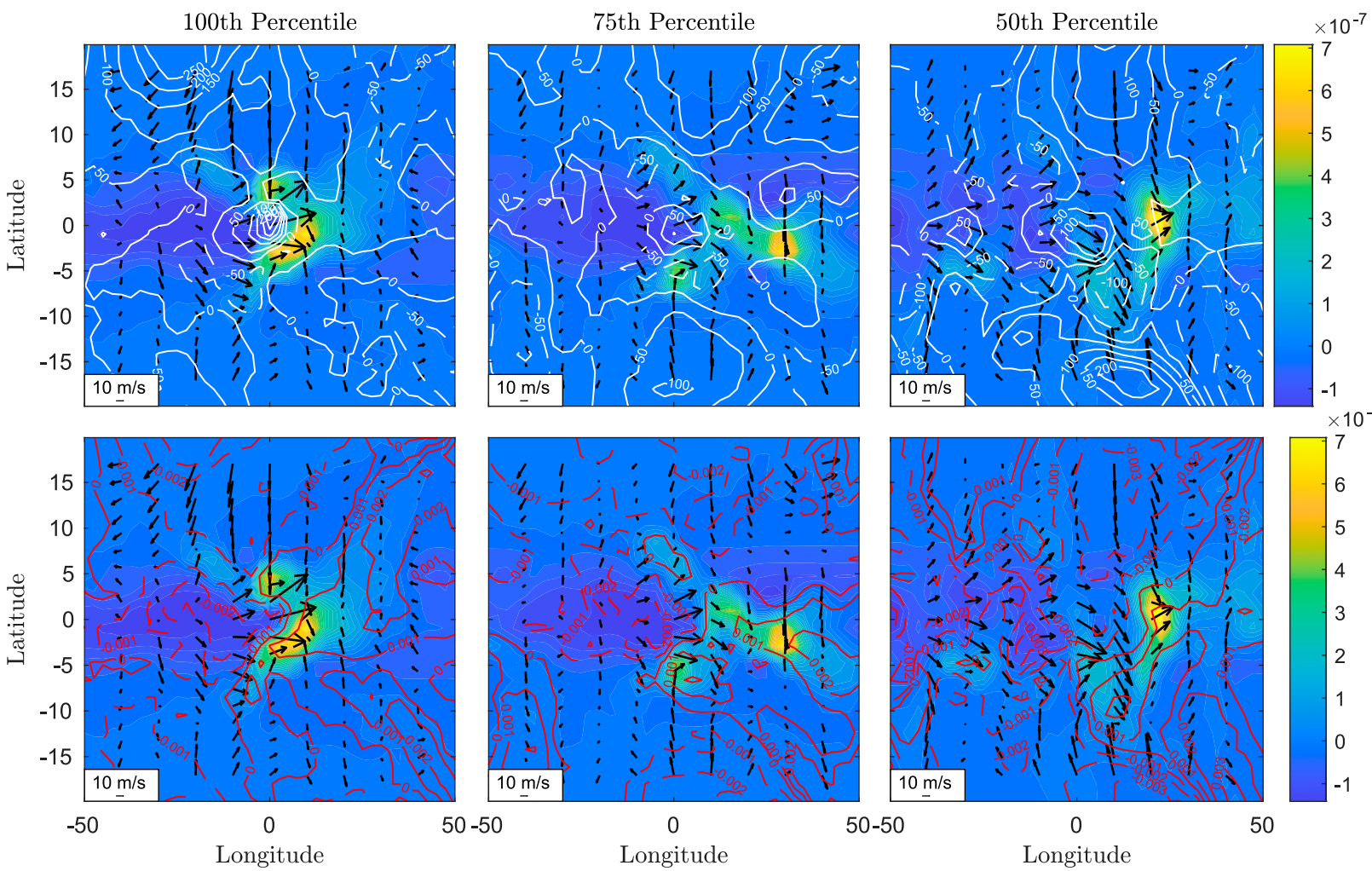

FIG. 10. Snapshots of three individual WWBs from the control run. (from left to right) WWBs of 100th, 75th, and 50th percentile peak wind strength. White and red contours indicate latent heat flux anomalies (unit $\mathrm{W} \mathrm{m}^{-2}$ ) and near-surface specific humidity anomalies (unitless), respectively. Shading indicates convective precipitation anomaly and arrows show the anomaly wind field.

the three experiments. The direction of propagation is opposite to that found by Lian et al. (2018), who found that WWBs propagate westward, a discrepancy that may have to do with the idealized setup used here versus the realistic configuration used in this other study, and understanding the reason for this would require further work. Figure 9 shows Hovmöller diagrams of convective precipitation, latent heat flux, and surface specific humidity from three experiments: the control run, fixed radiation, and fixed $v_{\text {mag }}$ in the bulk formula for latent heat flux. This figure demonstrates that the eastward propagation at around 15 to $20 \mathrm{~m} \mathrm{~s}^{-1}$ is also not affected by the elimination of the radiation feedbacks. The propagation speed is the same between the control and fixed radiation experiment, but is somewhat slower for the case of fixed $v_{\text {mag }}$, suggesting that WISHE not only amplifies the events but also contributes to their propagation mechanism. This is possibly related to the mechanism by which wind-evaporation feedbacks have been found to slow the eastward propagation of the MJO by partially counteracting eastward MSE advection anomalies (Kiranmayi and Maloney 2011). It is interesting to note that the recent mechanism of Hayashi and Itoh (2017) for eastward propagating anomalies did not include WISHE as part of the dynamics.

Finally, having gained some insight into the main feedbacks participating in the creation and amplification of WWBs, and in order to demonstrate some of the variability of WWBs in addition to the above analysis of composites, Fig. 10 shows snapshots of anomalous latent heat flux and specific humidity from three individual events of differing strength from the control run. This figure shows that the strongest events are associated with more pronounced, more symmetric cyclonic wind anomalies, and with stronger advection of drier air from midlatitudes toward the WWB. These individual events have the general character of observed WWBs in spite of the highly idealized aquaplanet configuration, and are consistent with realistic simulation using the Community Atmosphere Model (Lian et al. 2018). This raises the hope that the dynamical insights obtained here may be relevant to the real world.

\section{Conclusions}

Westerly wind bursts (WWBs) are an important forcing of El Niño events, and while prior work has 
associated WWBs with enhanced convection, tropical cyclones, cold surges from midlatitudes, and the MJO, the mechanism of WWBs is still not satisfactorily understood. In the present work, we used an idealized zonally symmetric aquaplanet model with a slab ocean model to identify and study the essential ingredients of the WWB mechanism. We find that convective heating and surface evaporation, and the WISHE feedback in particular, are very important in explaining the frequency and magnitude of WWBs, while radiative feedbacks and sensible surface heat flux are of lesser importance. We find that interactive surface latent heat flux fluxes, even in the absence of WISHE, still play a role in exciting WWBs, but that the WISHE feedback then leads to a strong amplification near the peak of the event. Additionally, we find that the advection of dry air from the cooler midlatitudes toward the WWB and the advection of moist air from the WWB area poleward both create significant latent heat signals, indicating that the meridional structure of the SST plays a role in WWB dynamics.

Our results are broadly in agreement with previous works regarding the importance of convective heating to WWBs. We found that composited WWBs appear to be baroclinic, in agreement with the work of Nitta and Motoki (1987), who found that WWBs were associated with abrupt enhancement of convective activity, and Fasullo and Webster (2000), who found that strong WWBs were significantly baroclinic. Furthermore, our composited WWBs show meridional convergence of dry air from midlatitudes to the west of the convective center, supported by work of Chu (1988), who analyzed two WWBs and found that surges from the midlatitudes forced equatorial sea level pressure gradients, and were important to the formation of WWBs. Paired cyclones, which were found to result in the strongest, longest lasting, and most horizontally extensive WWBs (Keen 1987; Hartten 1996; Moustaoui et al. 2002), were also observed in association with many of the strongest WWBs in our simulations. The structure of our WWBs, particularly those characterized by such paired cyclones, was found to have considerable resemblance to the optimal perturbations for intermediate ENSO models (Moore and Kleeman 1999). The difference between the eastward propagating WWBs found in our simulation and the westward propagation found in the realistic configuration of Lian et al. (2018) is possibly due to one of our idealizations, and this difference requires further investigation.

Atmospheric Kelvin waves are observed in our simulation. WWBs and Kelvin waves both propagate east at roughly $15-20 \mathrm{~m} \mathrm{~s}^{-1}$. We note some differences between our observed WWBs and convectively coupled Kelvin waves (CCKWs). For instance, Fig. 6 of Straub and Kiladis (2003) shows that CCKWs should be characterized by a latent heat flux anomaly to the east of the convection center, a feature of WISHE theories applied to both the MJO and CCKW (Emanuel 1987). This theory was shown to be flawed in the context of MJO, since "however, that, on average, maximum surface evaporation is in or to the west of the convective center of the MJO where its surface westerly wind" (Zhang 2005, p. 13). Similarly, in our simulations, the latent heat flux is found to the west of the convective center, disagreeing with these models of CCKWs. Furthermore, to the east of the westerly wind anomaly, no corresponding easterly wind anomaly is observed in our simulated WWBs, again disagreeing with most models of CCKWs. For these reasons, we believe that the two phenomena should be considered separately. Furthermore, a recent paper by Puy et al. (2016) that studied WWBs and their connection to convectively coupled waves and the MJO found no statistical correlation between WWBs and convectively coupled Kelvin waves.

We attempted to identify the main feedbacks that participate in the dynamics of WWBs using a highly idealized atmospheric model in an aquaplanet configuration. This allowed us to more easily identify the $3 \mathrm{D}$ structure of the wind event and perform compositing on a large number of events. Crucially, we were able to turn off different atmospheric feedbacks and processes to understand their importance to the WWB mechanism. We omitted interactive SST, zonal SST gradients, the effects of ENSO, the seasonal cycle, continents, topography, and more. It would be useful to go back to a fuller model configuration and re-examine the insights obtained using the idealizations used here. At the same time, it can be also useful to further abstract the mechanism using a simpler model incorporating the ingredients identified here.

The MJO, the main source of tropical intraseasonal variability, has been hypothesized to impact WWB events. Slingo et al. (1999) found that the 1997/98 El Niño was characterized by strong WWBs embedded in the active phase of the MJO, while Kiladis et al. (1994) used longer-term data to show that the WWBs associated with convection on an MJO time scale were dynamically distinct from those associated with shorter time scale convective disturbances. Similarly, Fasullo and Webster (2000) distinguished between brief and sustained WWBs, and argued that sustained WWBs were unique to the MJO and possibly forced by the MJO's modulation of CAPE. Although the present work aimed to understand WWBs independently from the MJO, future work studying WWBs subject to 
MJO-like forcing, or in a model that produces a robust MJO, such as the Superparameterized Community Earth System Model (Randall et al. 2003; Grabowski 2001), could be used to better understand the interaction between MJO and WWBs.

The hope is that the combination of more realistic models together with simpler ones would lead to a more complete understanding of WWBs, and therefore of how they might change for different climate conditions. Given the importance of WWBs to ENSO, such knowledge may provide deeper insight into how ENSO may behave in different climate states.

Acknowledgments. This research was supported by the NSF Climate Dynamics program, Grant AGS-1622985, by the NSF P2C2 program, Grant OCE-1602864, and by the Harvard-UTEC fund. Eli Tziperman thanks the Weizmann Institute for its hospitality during parts of this work. The authors thank Gabriel Vecchi and Claudia Pasquero for helpful feedback.

\section{REFERENCES}

Barlow, M., A. Hoell, and F. Colby, 2007: Examining the wintertime response to tropical convection over the Indian Ocean by modifying convective heating in a full atmospheric model. Geophys. Res. Lett., 34, L19702, https://doi.org/10.1029/ 2007GL030043.

Bony, S., and K. A. Emanuel, 2005: On the role of moist processes in tropical intraseasonal variability: Cloud-radiation and moisture-convection feedbacks. J. Atmos. Sci., 62, 2770-2789, https://doi.org/10.1175/JAS3506.1.

Chao, W. C., and L. Deng, 1998: Tropical intraseasonal oscillation, super cloud clusters, and cumulus convection schemes. Part II: 3D aquaplanet simulations. J. Atmos. Sci., 55, 690-709, https:// doi.org/10.1175/1520-0469(1998)055<0690:TIOSCC >2.0.CO;2.

Chen, S., R. Houze, and B. Mapes, 1996: Multiscale variability of deep convection in relation to large-scale circulation in TOGA COARE. J. Atmos. Sci., 53, 1380-1409, https://doi.org/ 10.1175/1520-0469(1996)053<1380:MVODCI>2.0.CO;2.

Chiodi, A. M., D. E. Harrison, and G. A. Vecchi, 2014: Subseasonal atmospheric variability and El Niño waveguide warming: Observed effects of the Madden-Julian oscillation and westerly wind events. J. Climate, 27, 3619-3642, https://doi.org/ 10.1175/JCLI-D-13-00547.1.

Chu, P.-S., 1988: Extratropical forcing and the burst of equatorial westerlies in the western Pacific: A synoptic study. J. Meteor. Soc. Japan, 66, 549-564, https://doi.org/10.2151/jmsj1965.66.4_ 549.

Eisenman, I., L. S. Yu, and E. Tziperman, 2005: Westerly wind bursts: ENSO's tail rather than the dog? J. Climate, 18, 52245238, https://doi.org/10.1175/JCLI3588.1.

Emanuel, K. A., 1986: An air-sea interaction theory for tropical cyclones. Part I: Steady-state maintenance. J. Atmos. Sci., 43, 585-605, https://doi.org/10.1175/1520-0469(1986)043<0585: AASITF $>2.0 . \mathrm{CO} ; 2$.

_ 1987: An air-sea interaction model of intraseasonal oscillations in the tropics. J. Atmos. Sci., 44, 2324-2340, https://doi.org/ 10.1175/1520-0469(1987)044<2324:AASIMO>2.0.CO;2.
Fasullo, J., and P. J. Webster, 2000: Atmospheric and surface variations during westerly wind bursts in the tropical western Pacific. Quart. J. Roy. Meteor. Soc., 126, 899-924, https:// doi.org/10.1002/qj.49712656407.

Gebbie, G., and E. Tziperman, 2009a: Incorporating a semistochastic model of ocean-modulated westerly wind bursts into an ENSO prediction model. Theor. Appl. Climatol., 97, 65-73, https://doi.org/10.1007/s00704-008-0069-6.

- , and $-2009 \mathrm{~b}$ : Predictability of SST-modulated westerly wind bursts. J. Climate, 22, 3894-3909, https://doi.org/10.1175/ 2009JCLI2516.1.

, I. Eisenman, A. T. Wittenberg, and E. Tziperman, 2007: Modulation of westerly wind bursts by sea surface temperature: A semi-stochastic feedback for ENSO. J. Atmos. Sci., 64, 3281-3295, https://doi.org/10.1175/JAS4029.1.

Giese, B., and D. Harrison, 1991: Eastern equatorial Pacific response to three composite westerly wind types. J. Geophys. Res., 96, 3239-3248, https://doi.org/10.1029/90JC01861.

Gill, A. E., 1980: Some simple solutions for heat-induced tropical circulation. Quart. J. Roy. Meteor. Soc., 106, 447-462, https:// doi.org/10.1002/qj.49710644905.

Grabowski, W. W., 2001: Coupling cloud processes with the largescale dynamics using the cloud-resolving convection parameterization (CRCP). J. Atmos. Sci., 58, 978-997, https://doi.org/ 10.1175/1520-0469(2001)058<0978:CCPWTL > 2.0.CO;2.

Harrison, D. E., and B. S. Giese, 1991: Episodes of surface westerly winds as observed from islands in the western tropical Pacific. J. Geophys. Res., 96, 3221-3237, https://doi.org/10.1029/ 90JC01775.

- and G. A. Vecchi, 1997: Westerly wind events in the tropical Pacific, 1986-95. J. Climate, 10, 3131-3156, https://doi.org/ 10.1175/1520-0442(1997)010<3131:WWEITT>2.0.CO;2.

Hartten, L. M., 1996: Synoptic settings of westerly wind bursts. J. Geophys. Res., 101, 16 997-17 019, https://doi.org/10.1029/ 96JD00030.

Hayashi, M., and H. Itoh, 2017: A new mechanism of the slow eastward propagation of unstable disturbances with convection in the tropics: Implications for the MJO. J. Atmos. Sci., 74, 3749-3769, https://doi.org/10.1175/JAS-D-16-0300.1.

Hayashi, Y.-Y., and A. Sumi, 1986: The 30-40 day oscillations simulated in an "aqua planet" model. J. Meteor. Soc. Japan, 64, 451-467, https://doi.org/10.2151/jmsj1965.64.4_451.

Held, I. M., and M. J. Suarez, 1994: A proposal for the intercomparison of the dynamical cores of atmospheric general circulation models. Bull. Amer. Meteor. Soc., 75, 1825-1830, https://doi.org/10.1175/1520-0477(1994)075<1825: APFTIO $>2.0 . \mathrm{CO} ; 2$.

Hendon, H. H., M. C. Wheeler, and C. Zhang, 2007: Seasonal dependence of the MJO-ENSO relationship. J. Climate, 20, 531543, https://doi.org/10.1175/JCLI4003.1.

Jin, F.-F., L. Lin, A. Timmermann, and J. Zhao, 2007: Ensemblemean dynamics of the ENSO recharge oscillator under statedependent stochastic forcing. Geophys. Res. Lett., 34, L03807, https://doi.org/10.1029/2006GL027372.

Keen, R. A., 1982: The role of cross-equatorial tropical cyclone pairs in the Southern Oscillation. Mon. Wea. Rev., 110, 1405-1416, https://doi.org/10.1175/1520-0493(1982)110<1405: TROCET $>2.0 . \mathrm{CO} ; 2$.

1987: Equatorial westerlies and the southern oscillation. Proceedings of the US TOGA western Pacific air-sea interaction workshop. Honolulu, HI, UCAR, 121-140.

Kessler, W. S., and R. Kleeman, 2000: Rectification of the Madden-Julian oscillation into the ENSO cycle. J. Climate, 13, 
3560-3575, https://doi.org/10.1175/1520-0442(2000)013<3560: ROTMJO $>2.0 . \mathrm{CO} ; 2$.

— M. J. McPhaden, and K. M. Weickmann, 1995: Forcing of intraseasonal Kelvin waves in the equatorial Pacific. J. Geophys. Res., 100, $10613-10631$, https://doi.org/10.1029/ 95JC00382.

Kiladis, G. N., and M. Wheeler, 1995: Horizontal and vertical structure of observed tropospheric equatorial Rossby waves. J. Geophys. Res., 100, 22 981-22 997, https://doi.org/10.1029/ 95JD02415.

, G. A. Meehl, and K. M. Weickmann, 1994: Large-scale circulation associated with westerly wind bursts and deep convection over the western equatorial Pacific. J. Geophys. Res., 99, 18 527-18 544, https://doi.org/10.1029/94JD01486.

Kiranmayi, L., and E. Maloney, 2011: The intraseasonal moist static energy budget in reanalysis data. J. Geophys. Res., 116, D21117, https://doi.org/10.1029/2011JD016031.

Kleeman, R., 1991: A simple model of the atmospheric response to ENSO sea surface temperature anomalies. J. Atmos. Sci., 48, 3-19, https://doi.org/10.1175/1520-0469(1991)048<0003: ASMOTA $>2.0 . \mathrm{CO} ; 2$.

Latif, M., J. Biercamp, and H. von Storch, 1988: The response of a coupled ocean-atmosphere general circulation model to wind bursts. J. Atmos. Sci., 45, 964-979, https://doi.org/10.1175/ 1520-0469(1988)045<0964:TROACO > 2.0.CO;2.

Lengaigne, M., J. P. Boulanger, C. Menkes, G. Madec, P. Delecluse, E. Guilyardi, and J. Slingo, 2003: The March 1997 westerly wind event and the onset of the 1997/98 El Niño: Understanding the role of the atmospheric response. J. Climate, 16, 3330-3343, https://doi.org/10.1175/15200442(2003)016<3330:TMWWEA > 2.0.CO;2.

—, J.-P. Boulanger, C. Menkes, P. Delecluse, and J. Slingo, 2004a: Westerly wind events in the tropical Pacific and their influence on the coupled ocean-atmosphere system: A review. Earth's Climate: The Ocean-Atmosphere Interaction, Geophys. Monogr., Vol. 147, Amer. Geophys. Union, 49-69, https://doi.org/10.1029/147GM03.

— E. Euilyardi, J. P. Boulanger, C. Menkes, P. Delecluse, P. Inness, J. Cole, and J. Slingo, 2004b: Triggering of El Niño by westerly wind events in a coupled general circulation model. Climate Dyn., 23, 601-620, https://doi.org/10.1007/ s00382-004-0457-2.

Lian, T., Y. Tang, L. Zhou, S. Ul Islam, C. Zhang, X. Li, and Z. Ling, 2018: Westerly wind bursts simulated in CAM4 and CCSM4. Climate Dyn., 50, 1353-1371, https://doi.org/10.1007/ s00382-017-3689-7.

Luther, D. S., D. E. Harrison, and R. A. Knox, 1983: Zonal winds in the central equatorial Pacific and El Niño. Science, 222, 327330, https://doi.org/10.1126/science.222.4621.327.

Ma, D., and Z. Kuang, 2016: A mechanism-denial study on the Madden-Julian oscillation with reduced interference from mean state changes. Geophys. Res. Lett., 43, 2989-2997, https://doi.org/10.1002/2016GL067702.

Madden, R. A., and P. R. Julian, 1971: Detection of a 40-50 day oscillation in zonal wind in tropical Pacific. J. Atmos. Sci., 28, 702-708, https://doi.org/10.1175/1520-0469(1971)028<0702: DOADOI $>2.0 . \mathrm{CO} ; 2$.

Matsuno, T., 1966: Quasi-geostrophic motions in the equatorial area. J. Meteor. Soc. Japan, 44, 25-43, https://doi.org/10.2151/ jmsj1965.44.1_25.

McPhaden, M. J., F. Bahr, Y. Du Penhoat, E. Firing, S. Hayes, P. Niiler, P. Richardson, and J. Toole, 1992: The response of the western equatorial Pacific Ocean to westerly wind bursts during November 1989 to January 1990. J. Geophys. Res. Oceans, 97, 14 289-14303, https://doi.org/10.1029/92JC01197.

Medeiros, B., D. L. Williamson, and J. G. Olson, 2016: Reference aquaplanet climate in the Community Atmosphere Model, version 5. J. Adv. Model. Earth Syst., 8, 406-424, https:// doi.org/10.1002/2015MS000593.

Moore, A. M., and R. Kleeman, 1999: Stochastic forcing of ENSO by the intraseasonal oscillation. J. Climate, 12, 11991220, https://doi.org/10.1175/1520-0442(1999)012<1199: SFOEBT $>2.0 . \mathrm{CO} ; 2$.

Moustaoui, M., H. Teitelbaum, C. Basdevant, and Y. Boughaleb, 2002: Linked behavior of twin tropical cyclones. J. Geophys. Res., 107, 4378, https://doi.org/10.1029/2000JD000066.

Neale, R., and B. J. Hoskins, 2000: A standard test for AGCMs including their physical parametrizations. II: Results for the Met Office model. Atmos. Sci. Lett., 1, 108-114.

— , and Coauthors, 2010: Description of the NCAR Community Atmosphere Model (CAM 4.0). NCAR Tech. Note NCAR/ TN-485+STR, 212 pp., www.cesm.ucar.edu/models/ccsm4.0/ cam/docs/description/cam4_desc.pdf.

Neelin, J. D., I. M. Held, and K. H. Cook, 1987: Evaporation-wind feedback and low-frequency variability in the tropical atmosphere. J. Atmos. Sci., 44, 2341-2348, https://doi.org/10.1175/ 1520-0469(1987)044<2341:EWFALF>2.0.CO;2.

Nitta, T., 1989: Development of a twin cyclone and westerly bursts during the initial phase of the 1986-87 El Niño. J. Meteor. Soc. Japan, 67, 677-681, https://doi.org/10.2151/jmsj1965.67.4_677.

_, and T. Motoki, 1987: Abrupt enhancement of convective activity and low-level westerly burst during the onset phase of the 1986-87 El Niño. J. Meteor. Soc. Japan, 65, 497-506, https:// doi.org/10.2151/jmsj1965.65.3_497.

Penland, C., and P. D. Sardeshmukh, 1995: The optimal-growth of tropical sea-surface temperature anomalies. J. Climate, $\mathbf{8}$ 1999-2024, https://doi.org/10.1175/1520-0442(1995)008<1999: TOGOTS $>2.0 . \mathrm{CO} ; 2$.

Perez, C. L., A. M. Moore, J. Zavala-Garay, and R. Kleeman, 2005: A comparison of the influence of additive and multiplicative stochastic forcing on a coupled model of ENSO. J. Climate, 18, 5066-5085, https://doi.org/10.1175/JCLI3596.1.

Perigaud, C. M., and C. Cassou, 2000: Importance of oceanic decadal trends and westerly wind bursts for forecasting El Niño. Geophys. Res. Lett., 27, 389-392, https://doi.org/10.1029/ 1999GL010781.

Puy, M., J. Vialard, M. Lengaigne, and E. Guilyardi, 2016: Modulation of equatorial Pacific westerly/easterly wind events by the Madden-Julian oscillation and convectively-coupled Rossby waves. Climate Dyn., 46, 2155-2178, https://doi.org/ 10.1007/s00382-015-2695-x.

Randall, D., M. Khairoutdinov, A. Arakawa, and W. Grabowski, 2003: Breaking the cloud parameterization deadlock. Bull. Amer. Meteor. Soc., 84, 1547-1564, https://doi.org/10.1175/ BAMS-84-11-1547.

Seiki, A., and Y. N. Takayabu, 2007a: Westerly wind bursts and their relationship with intraseasonal variations and ENSO. Part I: Statistics. Mon. Wea. Rev., 135, 3325-3345, https:// doi.org/10.1175/MWR3477.1.

_ , and — 2007b: Westerly wind bursts and their relationship with intraseasonal variations and ENSO. Part II: Energetics over the western and central Pacific. Mon. Wea. Rev., 135, 3346-3361, https://doi.org/10.1175/MWR3503.1.

Slingo, J., D. Rowell, K. Sperber, and E. Nortley, 1999: On the predictability of the interannual behaviour of the MaddenJulian oscillation and its relationship with El Niño. Quart. 
J. Roy. Meteor. Soc., 125, 583-609, https://doi.org/10.1002/ qj. 49712555411.

Sobel, A. H., E. D. Maloney, G. Bellon, and D. M. Frierson, 2010: Surface fluxes and tropical intraseasonal variability: A reassessment. J. Adv. Model. Earth Syst., 2 (2), https://doi.org/ 10.3894/JAMES.2010.2.2.

Straub, K. H., and G. N. Kiladis, 2003: The observed structure of convectively coupled Kelvin waves: Comparison with simple models of coupled wave instability. J. Atmos. Sci., 60, 1655-1668, https://doi.org/10.1175/1520-0469(2003)060<1655: TOSOCC $>2.0 . \mathrm{CO} ; 2$.

Sura, P., and P. D. Sardeshmukh, 2008: A global view of nonGaussian SST variability. J. Phys. Oceanogr., 38, 639-647, https://doi.org/10.1175/2007JPO3761.1.

Tziperman, E., and L. Yu, 2007: Quantifying the dependence of westerly wind bursts on the large scale equatorial Pacific SST J. Climate, 20, 2760-2768, https://doi.org/10.1175/JCLI4138a.1.

Vecchi, G. A., and D. E. Harrison, 1997: Westerly wind events in the tropical Pacific, 1986 1995: An atlas from the ECMWF operational surface wind fields. NOAA/Pacific Marine Environmental Laboratory Tech. Memo. ERL PMEL-109 (PB97-188213), $222 \mathrm{pp}$.

Yu, L., R. A. Weller, and T. W. Liu, 2003: Case analysis of a role of ENSO in regulating the generation of westerly wind bursts in the western equatorial Pacific. J. Geophys. Res., 108, 3128, https://doi.org/10.1029/2002JC001498.

Zavala-Garay, J., C. Zhang, A. Moore, and R. Kleeman, 2005: The linear response of ENSO to the Madden-Julian oscillation. J. Climate, 18, 2441-2459, https://doi.org/10.1175/JCLI3408.1.

Zebiak, S. E., 1982: A simple atmospheric model of relevance to El Niño. J. Atmos. Sci., 39, 2017-2027, https://doi.org/10.1175/ 1520-0469(1982)039<2017:ASAMOR > 2.0.CO;2.

Zhang, C., 1996: Atmospheric intraseasonal variability at the surface in the tropical western Pacific Ocean. J. Atmos. Sci., 53, 739-758, https://doi.org/10.1175/1520-0469(1996)053<0739: AIVATS $>2.0 . \mathrm{CO} ; 2$.

Zhang, C. D., 2005: Madden-Julian oscillation. Rev. Geophys., 43, RG2003, https://doi.org/10.1029/2004RG000158. 